\title{
The role of junior enterprises in the development of human resources in biotechnology: a case report in Rio De Janeiro state
}

\author{
Felipe Teixeira*, Debora Moretti, Daniela Uziel \\ From 5th Congress of the Brazilian Biotechnology Society (SBBIOTEC) \\ Florianópolis, Brazil. 10-14 November 2013
}

\section{Introduction}

Junior Enterprises are nonprofit entities run by undergraduate students. The Junior Enterprise Antonio Paes de Carvalho (EJ-APC) was established in 2010 with the major goal of stimulate the entrepreneurial skills of students in the life sciences area by the development of biotechnological products and services. Since human resources trained in basic science at the university are poorly incorporated into the private sector, we aim to demonstrate that new technologies can be developed or new markets can be achieved by the students in order to stimulate their professional career out of the academic locus.

\section{Methods}

Consists in the creation, establishment and management of the EJ-APC itself. The students incorporated as director can experience the daily work of an enterprise at all stages of its operation, from production to the presidency. Besides, students enrolled in products development can enhance their skills at the bench, using specific technologies.

\section{Results}

Since its inception, it has had four directories, yearly elected, and for selection processes for new members. In 2010, there was one single project line (polyclonas antibodies), whereas in 2013 we already run 4 different lines: polyclonal antibodies, academic histologic slides, platinated materials and genotyping. A series of changes in the structure and organization of the company were driven by directors: i) the creation of a complex selection process; ii) greater participation in MEJ (Junior Enterprise

Empresa Júnior Antônio Paes de Carvalho, Universidade Federal do Rio de Janeiro, Brazil 